\title{
Теоретические подходы к изучению инновационного финансирования в условиях улучшения инвестиционного климата
}

\author{
Екатерина Шеина ${ }^{1}$, Олим Астанакулов ${ }^{2 *}$ \\ ${ }^{1}$ Уральский государственный экономический университет, г. Екатеринбург, Россия \\ ${ }^{2}$ Ташкентский финансовый институт, г. Ташкент, Узбекистан
}

\author{
Информация о статье \\ Поступила в редакичию: \\ 26.06.2019 \\ Принята \\ к опубликованию: \\ 24.11.2019
}

УДК 3.33.336. 01

JEL G20, F44, O31

\begin{abstract}
Ключевые слова:
источники финансирования, инновации, инвестиционный климат, кредитование, лизинг, эмиссия ценных бумаг, венчурное финансирование, краудфандинг, краудлендинг, краудинвестинг
\end{abstract}

\section{Keywords:}

sources of financing, innovations, investment climate, crediting, leasing, issue of securities, venture financing, crowdfunding, crowdlending, crowdinvesting

\begin{abstract}
Аннотация
В статье рассматривается историческая эволючия и сравнительные характеристики методов финансирования, которые классифицируются авторами как традиционные, переходные и инновационные. В процессе исследования применяются методы причинно-следственного и структурнологического анализа, что позволяет перейти от теоретического обзора методов финансирования к изучению особенностей инновачионных источников финансирования на основе крауд-платформ с точки зрения ресурсов, инвесторов и механизма реализации. Полученнье результаты исследования подчеркивают значимость и необходимость внедрения новых финансовых технологий в рамках общей цүифровизации в части краудфандинга, краудинвестинга и краудлендинга в экономику России, что позволит обеспечить устойчивый экономический рост российским предприятиям.
\end{abstract}

Theoretical Approaches to Studying Innovative Financing Under the Conditions of the Investment Climate Improving

Ekaterina Sheina, Olim Astanakulov

\section{Abstract}

At all stages of the economy development and growth the issue of creating the system of financial sources, affordable and meeting the demands of the business entities financial activities, was one of the most acute. Fundamentally new sources and methods of the enterprises financing are being developed due to the world community entering the fourth industrial revolution. The traditional methods, such as bank lending, commercial lending, payables, leasing, factoring, venture financing and issuing securities can no longer be completely adequate to the occurring changes speed and mobility, including the financial sector and the field of capital formation. The authors of the article

\footnotetext{
* Автор для связи: E-mail: astanakulov@ gmail.com DOI: https://dx.doi.org/10.24866/2311-2271/2020-1/93-105
} 
considered the features of the modern financial market, analyzed the methods of financing depending on the period of financing (short-term, medium-term, long-term), as well as on the extent of the company treatment (internal and external sources). Based on the systematization and generalization of the scientific and practical ground in this area, the authors developed and logically proved their own classification of financing methods, conventionally divided into groups according to the historical chronology - traditional, transitional, and innovative. The most challenging from the point of view of the internet technologies development and the general digitalization of the economy are such forms as crowdfunding, crowdinvesting and crowdlending. The authors provided the comparative analysis of the funding sources which are included into these groups and proved the necessity for developing and introducing the crowding technologies into the country's economy. To understand and implement the practical mechanism for introducing the Crowd technologies into the modern financial sector of the Russian Federation, the authors analyzed the applicable regulatory framework and demonstrated the essentiality of introducing an appropriate federal legislation that would legalize the basic concepts in this area and would reduce the risks of the crowd transactions participants. As an illustration, confirming the possibility of introducing these financial instruments, the authors considered such factors as the volume of transactions and the main indicators of crowdfunding in the world. The recommendations of the authors are aimed at simplifying and accelerating Russia's joining the world of financial innovations, which would ensure sustainable economic growth for Russian enterprises.

\section{Введение}

Само явление «народного финансирования» давно известно человечеству: еще в XVIII в. в Европе писатели собирали средства на издание книг по подписке, а в России благодаря «народным деньгам» был возведен памятник Минину и Пожарскому [1]. Современный краудфандинг появился и активно развивается с начала 2000-х гг. благодаря появлению сети Интернет и электронных платежных систем, а в Россию эта идея пришла в 2010 г. и активно внедряется до сих пор. Актуальность данной темы объясняется современностью и нестандартностью краудфандинга как способа привлечения денежных средств, интересом к инструменту со стороны малого и среднего предпринимательства, а также отсутствием должного законодательного регулирования. Последнее является существенной проблемой для дальнейшего развития краудфандинга в стране. В марте 2018 г. был внесен законопроект «Об альтернативных способах привлечения инвестиций (краудфандинге)» на обсуждение в Государственную Думу Российской Федерации $[2,3]$. От того, насколько грамотно будет составлен будущий закон, зависит дальнейшая судьба краудфандинга как инструмента инвестирования и состояние экономики России.

Цель данного исследования заключается в оценке перспективы законодательного регулирования краудфандинга в России на основе существующих документов и зарубежного опыта.

Авторами были использованы нормативно-правовые акты Российской Федерации, публикационные материалы различных авторов, статистические данные и данные сети Интернет.

\section{Материалы и методы исследования}

Зарубежные авторы являются первооткрывателями в создании концептуальных основ инновационного финансирования и краудфандинга, в частности. Уместно привести работы J. Blach [4], P. Kavitha [5], R. Kleverlaan [6], N. Veron, G. Wolff [7] B. Zhang, R. Rau, M. Gray [8] и др. 
Исследователи Е. Гербер [9], С. Володин, Г. Жирнов, Р. Кадырова [10], А. Микрюков, Т. Решетникова, А. Серебренникова [11], М. Санин [12] рассматривают краудфандинг с точки зрения влияния данного инструмента финансирования на отдельные секторы экономики с методологической точки зрения - с целью пояснения принципа его работы. Но лишь некоторые исследователи, например, В.А. Кузнецов [13], сделали предложения по регулированию краудфандинга в России, что говорит о недостаточной изученности вопроса с юридической стороны.

Применяемые в статье методы исследования - диалектический, причинно-следственный и структурно-логический анализы - позволяют упорядочить теоретические аспекты применения краудфандинга, краудинвестинга и краудлдендинга как возможных альтернативных источников финансирования инновационных предприятий в Российской Федерации.

\section{Результаты исследования и их обсуждение}

Если рассматривать все время функционирования финансовых систем, можно отметить, что переломные моменты и выход на принципиально новый уровень развития наступали в периоды спада. В частности, после финансовоэкономического кризиса 2008-2009 гг. произошла революция в финансовой системе - актуализировался «Fintech» после почти 60-летней эволюции инноваций в финансовых услугах. Форсированный рост инновационного бизнеса, в частности, стартапов, вызванный ростом конкуренции на мировом и внутренних рынках, привел к развитию инновационного финансирования. Ведущие направления инновационного финансирования, такие как краудплатформы занимают главное место в развитии современных финансовых систем США, Европы и Китая.

Современная финансовая система зарождалось на протяжении веков, отталкиваясь от развития предпринимательства, тенденций индустриализации, а также влияния фаз различных финансово-экономических кризисов, исходя из функционирования и степени распространения методов финансирования, которые условно можно разделить на три группы: традиционные, переходные, инновационные (рис. 1).

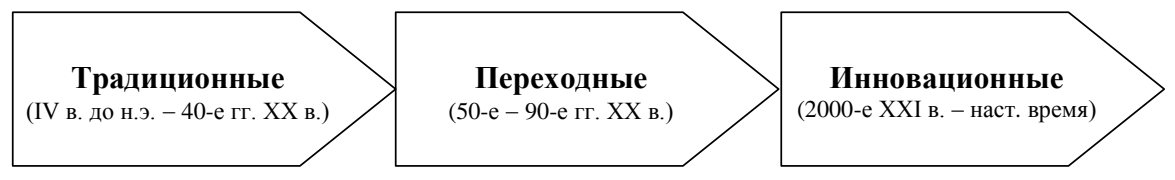

Рис.1. Классификация методов финансирования

Источник: составлено авторами

Основные компоненты современных финансовых систем выросли из небольших, локальных предпринимательских инициатив на самых ранних этапах экономической деятельности: торговцев средневековой эпохи, ювелиров Лондона XVII-го в., а также ярмарок и ранних товарных рынков, которые заполняли Европу. Новые формы финансовых учреждений, рынков и контрактов раз- 
вивались для удовлетворения более обширных и сложных потребностей в финансировании масштабных промышленных предприятий по всей Европе.

Группа традиционных методов финансирования (табл. 1) формировалась с ранних этапов развития финансовых систем до Второй мировой войны в XX в. За данный период были сформированы принципы функционирования современной банковской системы и финансовых рынков вместе с присущими им методами и инструментами финансирования.

Таблиия 1

\section{Традиционные методы финансирования}

\begin{tabular}{|c|c|c|}
\hline № & Методы финансирования & $\begin{array}{l}\text { Финансовый } \\
\text { инструмент }\end{array}$ \\
\hline 1 & $\begin{array}{l}\text { Кредит (creditium) - сумма денег, передаваемая одним участником дого- } \\
\text { вора о такой передаче другому участнику на условиях платности (в каче- } \\
\text { стве цены выступает процент), срочности (различаются кратко-, средне- и } \\
\text { долгосрочные К.) и безусловной возвратности (лат. creditum - заём от лат. } \\
\text { credere - доверять) }\end{array}$ & Кредитный договор \\
\hline 2 & $\begin{array}{l}\text { Лизинг (leasing) - долгосрочная аренда оборудования, обычно с правом } \\
\text { последующего выкупа. }\end{array}$ & Договор лизинга \\
\hline 3 & $\begin{array}{l}\text { Франчайзинг (franchise) - система, при которой один экономический } \\
\text { объект (например, фирма или даже государство) предоставляет другому } \\
\text { экономическому объекту право действовать на рынке от его имени и } \\
\text { часто под его именем (например, выпуск фирмой, вступающей в рынок, } \\
\text { своей продукции под маркой старой и более известной компании) }\end{array}$ & $\begin{array}{c}\text { Договор } \\
\text { коммерческой } \\
\text { концессии }\end{array}$ \\
\hline 4 & $\begin{array}{l}\text { Факторинг (factoring) - кредитование продаж поставщика факторинговой } \\
\text { компанией, которая становится собственником неоплаченных счетов- } \\
\text { фактур и принимает на себя риск их неоплаты, предварительно оплачива- } \\
\text { ет их и оказывает ряд услуг по защите от появления сомнительных долгов } \\
\text { и обеспечению гарантированного притока средств поставщику }\end{array}$ & $\begin{array}{c}\text { Договор } \\
\text { финансирования под } \\
\text { уступку денежного } \\
\text { требования }\end{array}$ \\
\hline 5 & $\begin{array}{l}\text { Форфейтинг (forfeiting) - посредническое финансирование купли/ прода- } \\
\text { жи дорогостоящих и уникальных основных фондов, особая форма сред- } \\
\text { несрочного коммерческого внешнеторгового кредитования, операция } \\
\text { продажи в кредит, которая представляет собой покупку кредитором фор- } \\
\text { фейтором долговых документов заёмщика «без права регресса» на любо- } \\
\text { го предыдущего держателя обязательств }\end{array}$ & $\begin{array}{c}\text { Договор } \\
\text { финансирования под } \\
\text { уступку денежного } \\
\text { требования }\end{array}$ \\
\hline 6 & $\begin{array}{l}\text { Эндаумент (endowment) - целевой фонд, предназначенный для использо- } \\
\text { вания в некоммерческих целях, как правило, для финансирования органи- } \\
\text { заций образования, медицины, культуры. Эндаумент наполняется пре- } \\
\text { имущественно за счет благотворительных пожертвований (англ. } \\
\text { endowment) }\end{array}$ & $\begin{array}{c}\text { Договор } \\
\text { пожертвования }\end{array}$ \\
\hline
\end{tabular}

Источник: составлено авторами по [14, 15]

Группа переходных методов финансирования (табл. 2) включает в себя методы, которые широко распространены в странах с развитой финансовой системой, и отсутствуют (либо слабо распространены) в развивающихся финансовых системах. Появление и развитие данных методов финансирования приходится на период 50-90-е гг. ХХ в.

Роль инноваций в экономическом, социальном и духовном развитии общества неоспорима. Общее определение инноваций объясняет, что они появляются в момент, когда внедряются новые идеи, решения и инструменты для изменения условий хозяйствующего субъекта и улучшения его положения [4], что повышает его конкурентоспособность и инвестиционную привлекательность. Представленные подходы к теории технологических инноваций могут быть адаптированы к теории финансовых инноваций. Однако необходимо учитывать особенности последней. Финансовые инновации не являются новым 
явлением, поскольку сопровождают технологические инновации с самого начала. Общеизвестно, что финансовые и технические инновации связаны друг с другом и со временем развиваются вместе. С одной стороны, финансовые инновации обеспечивают механизм финансирования инновационных технологических проектов, когда традиционные источники средств недоступны из-за высокого инвестиционного риска. С другой стороны, технический и экономический прогрессы, приводящие к усложнению бизнес-процессов и новым видам риска, заставляют финансовые систему и рынки адаптироваться к изменениям, модернизировать их в соответствии с новыми требованиями бизнесструктур и вызовами современного мира. Изменения рыночных условий приводят к формированию новых инструментов и созданию новых рынков и институтов, специализирующихся на этих разработках.

Таблицча 2

Переходные методы финансирования

\begin{tabular}{|c|c|c|}
\hline № & Методы финансирования & $\begin{array}{l}\text { Финансовый } \\
\text { инструмент }\end{array}$ \\
\hline 1 & $\begin{array}{l}\text { Секьюритизация (securitization) - процесс преобразования низко ликвид- } \\
\text { ных в ликвидные ценные бумаги, обращающиеся на рынке капитала }\end{array}$ & Ценные бумаги \\
\hline 2 & $\begin{array}{l}\text { Селенг (selling) - особая денежно-имущественная операция, состоящая в } \\
\text { передаче селенг-фирме за определенную плату своих прав на пользова- } \\
\text { ние и распоряжение имуществом (главным образом денежным) с безус- } \\
\text { ловным его возвратом по первому требованию }\end{array}$ & $\begin{array}{l}\text { Селенговый кон- } \\
\text { тракт }\end{array}$ \\
\hline 3 & $\begin{array}{l}\text { Фандрайзинг (fundraising) - Привлечение спонсорских финансовых } \\
\text { средств на осуществление конкретной программы, систематическая и } \\
\text { направленная деятельность организаций, включающая такие способы } \\
\text { привлечения средств, как обращение за грантами, организация благотво- } \\
\text { рительных мероприятий, сбор пожертвований и т.д }\end{array}$ & $\begin{array}{c}\text { Договор } \\
\text { пожертвования }\end{array}$ \\
\hline 4 & $\begin{array}{l}\text { Венчурное финансирование - финансирование новых предприятий и } \\
\text { новых видов деятельности, которые традиционно считаются высоко } \\
\text { рискованными, что не позволяет получить для них финансирование в } \\
\text { виде банковского кредита и других общепринятых источников }\end{array}$ & $\begin{array}{l}\text { Венчурное инве- } \\
\text { стиционное согла- } \\
\text { шение (договор) }\end{array}$ \\
\hline
\end{tabular}

Источник: составлено авторами по [14, 16]

Финансовые инновации Fintech, которые эволюционировали на протяжении XX в., внесли значительный вклад в повышение эффективности и автоматизации финансовых услуг: введение кредитных карт в 1950-х гг., банкоматов - в 1960-х гг., электронной торговли акциями - в 1970-х гг., мэйнфреймов и более совершенных систем учета - в 1980-х гг., интернетбанкинга и онлайн-брокерских услуг - в 1990-х гг.

С распространением интернета и мобильных устройств, инновации стали более интенсивными. В 2000-х гг. были представлены мобильные кошельки, платежные приложения, робо-консультанты, краудфандинг и платформы Р2P [17].

Основными направлениями финансирования бизнеса в Fintech являются краудфандинг, краудинвестинг и краудлендинг, которые формируют группу методов инновационного финансирования (табл. 3), появившихся в XXI в. и ставших актуальными после мирового финансовоэкономического кризиса 2008-2009 гг. 
Таблица 3

Инновационнье методы финансирования

\begin{tabular}{|c|c|c|}
\hline № & Методы финансирования & $\begin{array}{c}\text { Финансовый } \\
\text { инструмент }\end{array}$ \\
\hline 1 & $\begin{array}{l}\text { Краудфа́ндинг (народное финансирование, от англ. crowd funding, crowd - } \\
\text { «толпа», funding - «финансирование») - это коллективное сотрудничество } \\
\text { людей, которые добровольно объединяют свои деньги или другие ресурсы } \\
\text { вместе, как правило через Интернет, чтобы поддержать усилия других людей } \\
\text { или организаций. Сбор средств может служить для различных целей - помощь } \\
\text { пострадавшим от стихийных бедствий, поддержка со стороны болельщиков, } \\
\text { поддержка политических кампаний и т.д. }\end{array}$ & $\begin{array}{c}\text { Договор } \\
\text { пожертвования }\end{array}$ \\
\hline 2 & $\begin{array}{l}\text { Краудинвестинг (народное инвестирование, от англ. crowd investing, crowd - } \\
\text { «толпа», investing - «инвестирование») - это коллективное сотрудничество } \\
\text { миноритарных инвесторов, которые добровольно инвестируют свои деньги или } \\
\text { другие ресурсы вместе, как правило через Интернет, чтобы финансировать } \\
\text { стартап-компании и малый бизнес для получения прибыли от совместных ин- } \\
\text { вестиций или же доли в уставном (акционерном) капитале }\end{array}$ & $\begin{array}{c}\text { Инвестицион- } \\
\text { ный договор }\end{array}$ \\
\hline 3 & $\begin{array}{l}\text { Краудлендинг (народное кредитование, от англ. Crowd lending, crowd - «тол- } \\
\text { па», lending - «кредитование») - это коллективное сотрудничество кредиторов, } \\
\text { которые добровольно инвестируют свои деньги или другие ресурсы вместе, как } \\
\text { правило через Интернет, чтобы финансировать стартап-компании и малый } \\
\text { бизнес для получения процентов по выданным кредитам. Краудлендинг возмо- } \\
\text { жен в } 4 \text { комбинациях: P2P (Peer to Peer - «Равный равному»), В2В (Business to } \\
\text { Business - «Бизнес Бизнесу»), P2В (People to Business - «Физические лица Биз- } \\
\text { несу»), В2P (Business to People - «Бизнес Физическим лицам») }\end{array}$ & $\begin{array}{c}\text { Кредитный } \\
\text { договор }\end{array}$ \\
\hline
\end{tabular}

Источник: составлено авторами

Механизм работы вышеперечисленных методов инновационного финансирования практически одинаков по своей сути, однако отличается по субъектам и предметам отношений. В центре данных отношений находятся крауд-платформы (рис. 2).

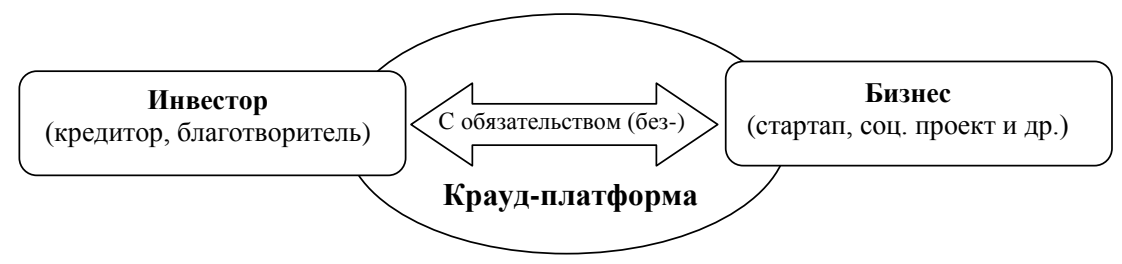

Pис.2. Механизм функционирования крауд-платформ

Источник: составлено авторами

Анализ научной литературы по традиционным, переходным и инновационным методам финансирования дал возможность составить сравнительные характеристики указанных методов (табл. 4).

Ключевые особенности и отличия каждого вида крауд-финансирования представлены авторами далее в табл. 5.

Принцип работы краудфандинга распространяется на все виды данной категории: лицо, которому нужны средства на реализацию своего проекта, регистрируется на соответствующей площадке, предоставляет всю требуемую информацию, проходит соответствующие проверки, заполняет свой профиль на сайте, четко описывает проект и ждет инвесторов, готовых в него вложиться. Между инвестором и предпринимателем заключается договор в 
электронном виде, который оговаривает права и обязанности двух сторон, фиксирует сумму, вложенную инвестором, сроки исполнения, риски и вознаграждение инвестора [21].

Таблииа 4

Сравнительный анализ методов финансирования

\begin{tabular}{|l|l|l|}
\hline \multicolumn{1}{|c|}{$\begin{array}{c}\text { Характеристики методов } \\
\text { финансирования }\end{array}$} & $\begin{array}{c}\text { Традиционные и переходные } \\
\text { методы финансирования }\end{array}$ & \multicolumn{1}{|c|}{$\begin{array}{c}\text { Инновационные методы } \\
\text { финансирования }\end{array}$} \\
\hline Субъекты финансирования & $\begin{array}{l}\text { все участники финансового } \\
\text { рынка (в основном банки) }\end{array}$ & $\begin{array}{l}\text { физические и юридические } \\
\text { лица }\end{array}$ \\
\hline Объекты финансирования & все формы бизнеса & малый и средний бизнес \\
\hline Инструменты финансирования & $\begin{array}{l}\text { банковские инструменты } \\
\text { финансирования и инструменты } \\
\text { фондового рынка }\end{array}$ & инструменты крауд-платформ \\
\hline Вид предоставления услуг & офлайн и онлайн & онлайн \\
\hline Объем финансирования & большой & маленький (средний) \\
\hline $\begin{array}{l}\text { Уровень доходности } \\
\text { финансирования }\end{array}$ & $\begin{array}{l}\text { умеренный (в зависимости от } \\
\text { ставки рефинансирования) }\end{array}$ & $\begin{array}{l}\text { высокий (в зависимости от } \\
\text { риска и перспектив проекта) }\end{array}$ \\
\hline Степень риска финансирования & низкий (средний) & $\begin{array}{l}\text { высокий (средний, } \\
\text { в зависимости от проекта) }\end{array}$ \\
\hline $\begin{array}{l}\text { Скорость процесса } \\
\text { финансирования }\end{array}$ & $\begin{array}{l}\text { медленный (высокая степень } \\
\text { бюрократии) }\end{array}$ & $\begin{array}{l}\text { быстрый (онлайн сбор } \\
\text { и обработка информации) }\end{array}$ \\
\hline
\end{tabular}

Источник: составлено авторами

Таблица 5

Сравнение видов крауд-финансирования

\begin{tabular}{|c|c|c|c|}
\hline Критерий & Краудфандинг & Краудинвестинг & Краудлендинг \\
\hline Tип проекта & $\begin{array}{l}\text { Творческие, социально- } \\
\text { го характера }\end{array}$ & $\begin{array}{l}\text { Стартапы, } \\
\text { бизнес-проекты (долго- } \\
\text { срочное инвестирова- } \\
\text { ние) }\end{array}$ & $\begin{array}{l}\text { Бизнес-проекты, } \\
\text { покрытие текущих } \\
\text { расходов организации } \\
\text { (краткосрочное } \\
\text { инвестирование) }\end{array}$ \\
\hline Требуемые ресурсы & \multicolumn{3}{|c|}{ Денежные средства } \\
\hline $\begin{array}{l}\text { Инструментьл } \\
\text { финансирования } \\
\text { проекта }\end{array}$ & $\begin{array}{lr}\text { Перевод } & \text { определенного } \\
\text { объема } & \text { денежных } \\
\text { средств без } & \text { возврата } \\
\text { данной суммы } & \end{array}$ & $\begin{array}{l}\text { Заем, продажа доли } \\
\text { компании, } \\
\text { ценных бумаг, токены } \\
\text { (ICO) }\end{array}$ & Заем \\
\hline Инвесторьл & \multicolumn{3}{|c|}{ Физические лица, юридические лица } \\
\hline $\begin{array}{l}\text { Субъекты, } \\
\text { привлекаюшчие } \\
\text { инвестиции }\end{array}$ & $\begin{array}{l}\text { Физические лица, } \\
\text { творческие } \\
\text { и социальные } \\
\text { объединения, } \\
\text { малый, средний бизнес }\end{array}$ & $\begin{array}{l}\text { Малый, средний, } \\
\text { крупный бизнес }\end{array}$ & $\begin{array}{l}\text { Малый, средний, } \\
\text { крупный бизнес }\end{array}$ \\
\hline $\begin{array}{l}\text { Вознаграждение } \\
\text { инвесторов }\end{array}$ & $\begin{array}{l}\text { Результат проекта, } \\
\text { сувенирная продукция, } \\
\text { благодарность }\end{array}$ & $\begin{array}{l}\text { Доля в капитале, } \\
\text { дивиденды } \text { от акций, } \\
\text { купонный доход от } \\
\text { облигаций, доход от } \\
\text { обращения } \\
\text { бирженов на криптовалюты }\end{array}$ & $\begin{array}{l}\text { Возврат инвестиро- } \\
\text { ванной суммы с на- } \\
\text { численными процен- } \\
\text { тами }\end{array}$ \\
\hline
\end{tabular}

Источник: составлено авторами по [18-20]

С 2015 г. общий объем сделок через краудфандинг возрос до 11 млрд руб., согласно данным Центрального банка Российской Федерации (рис. 3). Это говорит о высокой степени заинтересованности людей в новом инструменте инвестирования. 


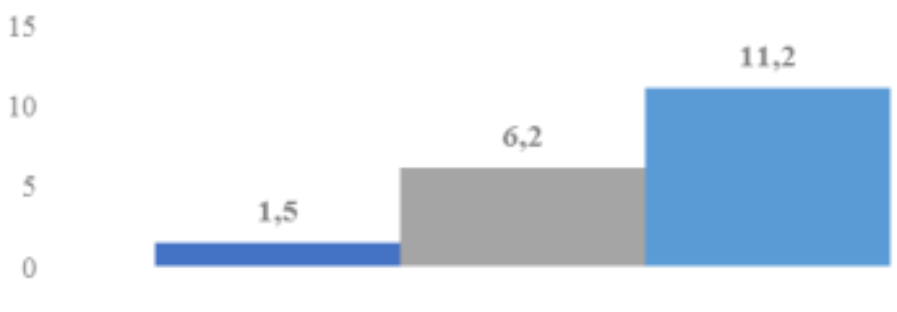

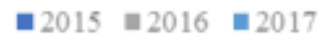

Рuс. 3. Объем сделок по краудфандингу, млрд руб. Источник: составлено авторами по [22, 23]

Инвестиции в капитал за 3 года возросли в 8 раз, а количество инвесторов увеличилось до 14,5 тыс. человек. Наблюдается постоянный рост количества компаний, успешно реализовавших свои проекты с помощью крауд-технологий (табл. 6).

Таблица 6

Основные показатели рынка краудфандинга в мире за 2015-2017 22.

\begin{tabular}{|l|c|c|c|c|}
\hline \multicolumn{1}{|c|}{ Показатель } & $\mathbf{2 0 1 5}$ & $\mathbf{2 0 1 6}$ & $\mathbf{2 0 1 7}$ & Изменение, \% \\
\hline Инвестиции в капитал, млн. руб. & 232,0 & 1505,5 & 1837,7 & $691,8 \%$ \\
\hline Профинансированные компании, шт. & 81 & 277 & 871 & $975,3 \%$ \\
\hline Количество инвесторов, чел. & 105 & 1313 & 14466 & $13677,1 \%$ \\
\hline
\end{tabular}

Источник: составлено авторами по [24]

Особенность краудфандинга в России заключается в том, что данную возможность используют организации оптовой и розничной торговли, а не только IT-компании. Отраслевая структура организаций, привлекающих средства через краудфандинг представлена на рис. 4.

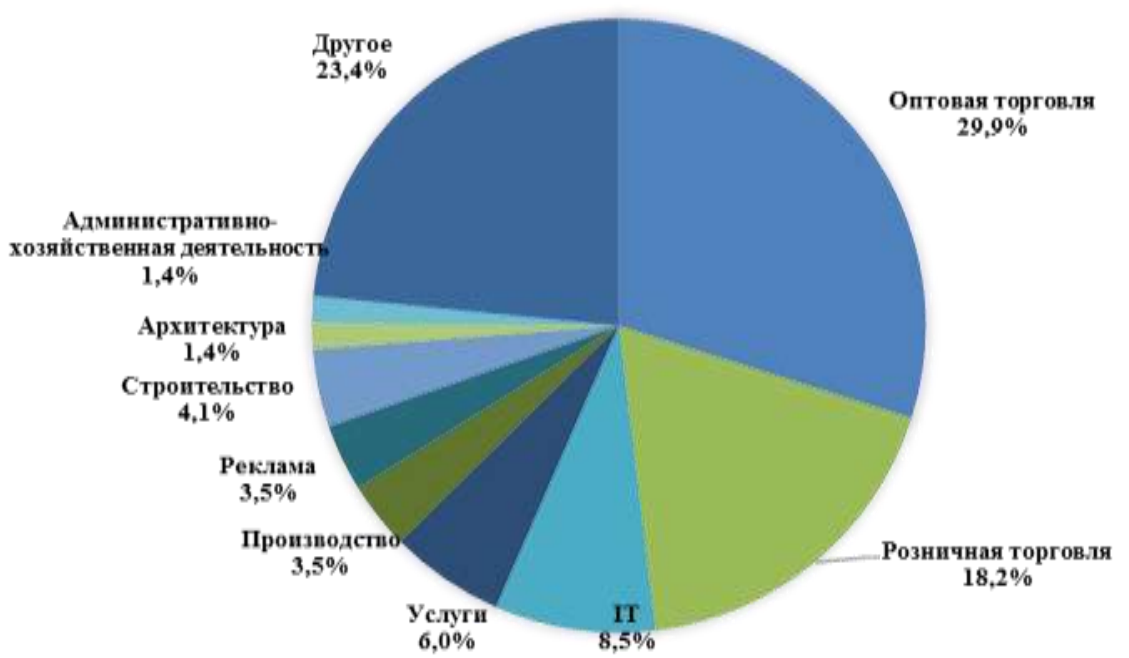

Puc. 4. Отраслевая структура компаний, финансируемых через краудфандинг Источник: составлено авторами по [24] 
На сегодняшний день на российском крауд-рынке присутствуют достаточно успешные платформы, такие как StrartTrack, Venture Club, Поток, Planeta.ru и др. Все они отличаются друг от друга по разным критериям: так StartTrack будет привлекателен для инновационных стартапов и развития малых предприятий, в то время как Planeta.ru открыта для социальных и творческих проектов. Немаловажен факт размера комиссии для авторов проектов, что является одним из основных критериев выбора площадки (табл. 7).

Таблий 7

Основные краудфандинговые площадки России

\begin{tabular}{|l|l|c|c|c|c|c|}
\hline $\begin{array}{c}\text { Название } \\
\text { площадки }\end{array}$ & $\begin{array}{c}\text { Вид финанси- } \\
\text { рования }\end{array}$ & $\begin{array}{c}\text { Совокуп- } \\
\text { ный оборот, } \\
\text { млн руб. }\end{array}$ & $\begin{array}{c}\text { Средний } \\
\text { объм инве- } \\
\text { стиций на } \\
\text { одну компа- } \\
\text { нию, млн } \\
\text { руб. }\end{array}$ & $\begin{array}{c}\text { Средний чек } \\
\text { на одну } \\
\text { компанию от } \\
\text { инвестора, } \\
\text { тыс. руб. }\end{array}$ & $\begin{array}{c}\text { Количество } \\
\text { инвесторов } \\
\text { в одной } \\
\text { компании }\end{array}$ & $\begin{array}{c}\text { Комиссия ком- } \\
\text { пании, \% }\end{array}$ \\
\hline StartTrack & $\begin{array}{l}\text { Краудинве- } \\
\text { стинг, крауд- } \\
\text { лендинг }\end{array}$ & 1498,0 & 22,0 & 426 & 52 & 5 \\
\hline Город денег & Краудлендинг & 465,8 & 1,0 & 420,0 & $2-3$ & $2-5,5$ \\
\hline Venture Сlub & $\begin{array}{l}\text { Краудинве- } \\
\text { стинг, крауд- } \\
\text { лендинг }\end{array}$ & 897,0 & 13,0 & 3000,0 & 4 & $1-5$ \\
\hline Поток & Краудлендинг & 714,4 & 0,5 & 4,5 & 115 & 6,7 \\
\hline Рlaпета.rи & Краудфандинг & 760,2 & 0,2 & 1,5 & 186 & $10-15$ \\
\hline
\end{tabular}

Источник: составлено авторами по [24]

\section{Выводы}

Краудфандинг способен решить многие насущные вопросы в российской экономике.

Во-первых, это еще один новый способ финансирования проектов малого и среднего предпринимательства, поскольку традиционные инструменты привлечения денежных средств в большинстве случаев недоступны по причине неспособности таких организаций предоставить обеспечение по своим обязательствам. Во-вторых, краудфандинговая платформа становится «инкубатором» для малого и среднего бизнеса и различных инновационных стартапов, так как дает возможность попробовать разные способы привлечения денег на самой платформе - от займа до эмиссии ценных бумаг.

Кроме того, краудфандинг может дать новую жизнь забытому венчурному инвестированию, поскольку круг инвесторов значительно расширится за счет физических лиц.

Следует отметить, что краудфандинг благоприятствует практическим всем сферам деятельности (в том числе и проблемным секторам): от творческой и социально-ориентированной до сельскохозяйственной и производственной, а также упрощает ношу основателей проектов, касающуюся рекламы своих проектов, продукции и компании. Они получают возможность дополнительных затрат рекламировать свою продукцию, используя «сарафанное радио» и СМИ, которые заинтересованы в обзоре новинок краудфандинговых проектов [13].

В результате это способствует реализации многих планов по стимулированию и реальному развитию малого и среднего предпринимательства в 
России, создает дополнительные рабочие места, а также формирует финансовую культуру среди населения, которое может выступать в этих отношениях как предпринимателем, так и инвестором. Это достаточно перспективное направление для развития новой России, чье становление происходит на наших глазах, однако сейчас существует ряд проблем, связанных с деятельностью краудфандинга в России.

Прежде всего, поскольку перечисление денежных средств в пользу проекта проводится через банковские карты, краудфандинговая платформа, не являясь кредитной организацией, по сути выполняет банковскую функцию эквайринга - операция с платежными картами, касающейся переводов денежных средств от инвесторов к инициаторам проектов [1]. Поэтому стоит вопрос об обязанностях и функциях самой крауд-площадки и возможности определения ей особого статуса в качестве проведения переводов денежных средств, либо найти иные способы передачи средств от инвестора к инициатору проекта.

Остается открытым вопрос, каким образом будут оформляться сделки на краудфандинговой площадке, если все процедуры осуществляются через сайт платформы, и как инвестор сможет убедиться, что площадка и сам проект не являются мошенничеством.

\section{Заключение}

По мнению авторов, указанные проблемы обусловлены отсутствием четкого законодательного регулирования. Поэтому для нормального функционирования краудфандинга необходимо создать такой федеральный закон, который четко определил бы предмет регулирования, основные понятия краудфандинга, а также смог решить все текущие проблемы, с которыми сталкиваются крауд-технологии сегодня. Часто адаптированный зарубежный опыт в регулировании может быть полезным для законотворчества, поэтому необходимо проводить анализ опыта других стран.

\section{Список источников / References}

1. Кузьменко В. Краудфандинг: история похождений в России. Rusbase, 2015. [Kuz'menko V. Kraudfanding: istoriya pokhozhdeniy v Rossii [Crowdfunding: a history of adventures in Russia]. Rusbase, 2015. Available at: https://rb.ru/opinion/crowd-russia (accessed 28.05.2019).

2. Законопроект «Об альтернативных способах привлечения инвестиций (краудфандинге)». Федеральный портал проектов нормативных правовых актов. [Zakonoproyekt «Ob al'ternativnykh sposobakh privlecheniya investitsiy (kraudfandinge)» [The bill "On alternative methods of attracting investments (crowdfunding)"]. Federal portal for draft regulatory legal acts. Available at: http://regulation.gov.ru (accessed 25.05.2019).

3. В Госдуму внесен законопроект о краудфандинге. Информационное телеграфное агентство России (ИТАР-ТАСС). [V Gosdumu vnesen zakonoproyekt o kraudfandinge [ A bill on crowdfunding has been submitted to the State Duma]. Information Telegraph Agency of Russia (ITAR-TASS). Available at: http://tass.ru (accessed 23.05.2019). 
4. Blach J. Financial innovations and their role in the modern financial system - identification and systematization of the problem. Financial Internet Quarterly "e-Finanse", 2011, vol. 7, no 3. pp. 13-26.

5. Kavitha P., Baag P. Crowdfunding for Entrepreneurs - analysis of the Institutional Work. Working Paper, 2018, pp. 1-30.

6. Kleverlaan R. Expanding the Crowdfunding Market in South East Europe. Available at: https://www.undp.org/content/dam/croatia (accessed 26.05.2019).

7. Veron N., Wolff G. Capital Markets Union: A Vision for the Long Term. Journal of Financial Regulation, Oxford University Press, 2016. no 2. pp. 130-153.

8. Zhang B., Wardrop R., Rau R., Gray M. Moving mainstream: benchmarking the European alternative. The Journal of Financial Perspectives: Fintech. EY Global Financial Services Institute, 2015. vol. 3, pp. 40.

9. Gerber E.M., Hui J. Crowdfunding: Motivations and deterrents for participation. ACM Transactions on Computer-Human Interaction (TOCHI), 2013, vol. 20 (6), no. 34. pp. 1-32.

10. Володин С., Жирнов Г., Кадырова Р. Краудинвестинг как новый способ венчурного финансирования. Валютное регулирование. Валютный контроль, 2017, №10, cc. 50-58. [Volodin S., Zhirnov G., Kadyrova R. Kraudinvesting kak noviy sposob venchurnogo finansirovaniya [Crowdinvesting as a new way of venture financing]. Valyutnoye regulirovaniye. Valyutnyy kontrol' = Currency regulation. Currency control, 2017, no. 10, pp. 50-58.]

11. Микрюков А.В., Решетникова Т.В., Серебренникова А.И. Краудфандинг: тенденции, перспективы развития и социальная значимость. Управление экономическими системами: электронный научный журнал, 2017, №12 (106), сс. 63-69. [Mikryukov A.V., Reshetnikova T.V., Serebrennikova A.I. Kraudfanding: tendentsii, perspektivy razvitiya i sotsial'naya znachimost' [Crowdfunding: trends, development prospects and social significance] Upravleniye ekonomicheskimi sistemami: elektronnyy nauchnyy zhurnal = Management of economic systems: electronic scientific journal, 2017, no. 12 (106). pp. 63-69.]

12. Санин М. История развития краудфандинга. Классификация видов. Анализ перспектив развития и преимуществ. Научный журнал НИУ ИТМО. Серия «Экономика и экологический менеджмент», 2015, №4, сс. 57-63. [Sanin M. Istoriya razvitiya kraudfandinga. Klassifikatsiya vidov. Analiz perspektiv razvitiya i preimushchestv [History of the development of crowdfunding. Classification of species. Analysis of development prospects and advantages] Nauchnyy zhurnal NIU ITMO. Seriya "Ekonomika i ekologicheskiy menedzhment" = Scientific journal NRU ITMO. Series "Economics and Environmental Management", 2015, no. 4, pp. 57-63.]

13. Кузнецов В.А. Краудфандинг: Актуальные вопросы регулирования. Деньги и кредum, 2017, №1, сc. 65-73. [Kuznetsov V.A. Kraudfanding: Aktual'nyye voprosy regulirovaniya [Crowdfunding: Actual issues of regulation], Den'gi $i$ kredit $=$ Money and credit, 2017, no. 1, pp. 65-73. Available at: http://www.cbr.ru (accessed 29.05.2019).

14. Словарь бизнес-терминов. Академик.ру. [Slovar' biznes-terminov. Akademik.ru [Glossary of business terms. Akademik.ru.], 2001. Available at: http://sbiblio.com/biblio/content.aspx?dictid=172\&wordid=1263257, (accessed 28.05.2019).

15. Лопатников Л.И. Экономико-математический словарь: Словарь современной экономической науки. Москва, Дело, 2003. [Lopatnikov L.I. Ekonomikomatematicheskiy slovar': Slovar' sovremennoy ekonomicheskoy nauki [Economics and mathematics dictionary: Dictionary of modern economics]. Moscow, Delo Publ., 2003. Available at: https://alleng.org/d/econ/econ268.htm, (accessed 26.05.2019). 
16. Финансовый словарь Финам. [Finansovyy slovar' Finam [Financial dictionary Finam] Available at: https://www.finam.ru/dictionary, (accessed 26.05.2019).

17. Шайдуллина В.К. Проблемы правового регулирования Р2Р-кредитования в Российской Федерации. Общество: политика, экономика, право, 2018, №5, cc. 96-99. Shaydullina V.K. Problemy pravovogo regulirovaniya P2P-kreditovaniya v Rossiyskoy Federatsii [Problems of legal regulation of P2P lending in the Russian Federation.] Obshchestvo: politika, ekonomika, pravo = Society: politics, economics, law, 2018, no. 5, pp. 96-99.] Available at: https://elibrary.ru, (accessed 26.05.2019).

18. Дрогичинская В.В. Практическое пособие по краудфандингу. Москва, 2018. Drogichinskaya V.V. Prakticheskoye posobiye po kraudfandingu [Practical Guide on Crowdfunding]. Moscow, 2018.] Available at: https://planeta.ru (accessed 23.05.2019).

19. Краудфандинг: как привлечь деньги с помощью коллективного финансирования. Информационно-просветительский ресурс ЦБ РФ Fincult.info. [Kraudfanding: kak privlech' den'gi s pomoshch'yu kollektivnogo finansirovaniya [Crowdfunding: how to raise money with the help of collective financing]. Information and educational resource of the Central Bank of the Russian Federation Fincult.info. Available at: https://fincult.info (accessed 27.05.2019).

20. Новые инструменты привлечения финансирования для развития технологических компаний: практика использования и перспективы развития в России. Национальный исследовательский университет Высшая школа экономики. [Novyye instrumenty privlecheniya finansirovaniya dlya razvitiya tekhnologicheskikh kompaniy: praktika ispol'zovaniya i perspektivy razvitiya $\mathrm{v}$ Rossii [New tools to attract financing for the development of technology companies: practice of use and development prospects in Russia]. National Research University Higher School of Economics. Available at: https://www.hse.ru (accessed 28.05.2019).

21. Тихонович Л. Краудфандинг: ограничивать или помогать. Филантроп - электронныц журнал благотворительности. [Tikhonovich L. Kraudfanding: ogranichivat' ili pomogat'. [Crowdfunding: to limit or help]. Filantrop - elektronnyy zhurnal blagotvoritel'nosti $=$ Philanthropist is an electronic charity magazine. Available at: http://philanthropy.ru, (accessed 26.05.2019).

22. Замолкин Д. Толпа инвесторов: что мешает расти российскому рынку краудфандинга. «Forbes Russia»- финансово-экономический журнал. [Zamolkin D. Tolpa investorov: chto meshayet rasti rossiyskomu rynku kraudfandinga [Crowd of investors: what prevents the Russian crowdfunding market from growing]. «Forbes Russia»-finansovo-ekonomicheskiy zhurnal. = Forbes Russia - financial and economic magazine. Available at: http://www.forbes.ru (accessed 26.05.2019).

23. Объем рынка краудфандинга в 2017 году увеличился в два раза. Пресс-служба ЦБ. [Ob"yem rynka kraudfandinga v 2017 godu uvelichilsya v dva raza [The volume of the crowdfunding market in 2017 doubled]. Press Service. Available at: https://www.cbr.ru (accessed 28.05.2019).

24. Богомолова А. Инфографика: как устроен рынок краудинвестинга в России. Inc - журнал о предпринимательстве. [Bogomolova A. Infografika: kak ustroyen rynok kraudinvestinga v Rossii [Infographics: how the crowdinvesting market in Russia works]. Inc - zhurnal o predprinimatel'stve = Inc - Journal of Entrepreneurship. Available at: https://incrussia.ru (accessed 24.05.2019). 


\section{Сведения об авторах / About authors}

Шеина Екатерина Георгиевна, кандидат экономических наук, доцент, доцент кафедры финансового менеджмента, Уральский государственный экономический университет. 620144 Россия, г. Екатеринбург, ул. 8 Марта/Народной Воли, 62/45. E-mail: shekat@mail.ru

Ekaterina G. Sheina, Candidate of Economic Sciences, Associate Professor, Associate Professor of Financial Management Department, Ural State University of Economics. 62/45, 8 Marta/ Narodnaya Volya Str., Ekaterinburg, Russia 620144.E-mail: shekat@mail.ru

Астанакулов Олим Таштемирович, кандидат экономических наук, доцент, начальник заочного отделения, Ташкентский финансовый институт. 100000 Узбекистан, г. Ташкент, ул. А. Темура, 60A. E-mail: astanakulov@gmail.com

Olim T. Astanakulov, Candidate of Economic Sciences, Associate Professor, Head of Extramural, Tashkent Institute of Finance. 60A, A. Temur Str., Tashkent, Uzbekistan 100000.

E-mail: astanakulov@gmail.com 